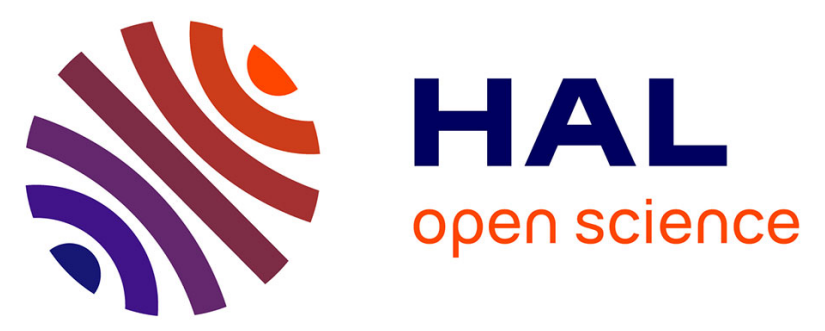

\title{
FEMTOSECOND INFRARED AND VISIBLE SPECTROSCOPY OF EXCESS ELECTRON IN NEAT DIMETHYLSULFIDE
}

\author{
Yann Gauduel, S. Pommeret, A. Antonetti, J. Belloni, J. Marignier
}

\section{- To cite this version:}

Yann Gauduel, S. Pommeret, A. Antonetti, J. Belloni, J. Marignier. FEMTOSECOND INFRARED AND VISIBLE SPECTROSCOPY OF EXCESS ELECTRON IN NEAT DIMETHYLSULFIDE. Journal de Physique IV Proceedings, 1991, 01 (C5), pp.C5-161-C5-166. 10.1051/jp4:1991520 . jpa00250644

\section{HAL Id: jpa-00250644 https://hal.science/jpa-00250644}

Submitted on 1 Jan 1991

HAL is a multi-disciplinary open access archive for the deposit and dissemination of scientific research documents, whether they are published or not. The documents may come from teaching and research institutions in France or abroad, or from public or private research centers.
L'archive ouverte pluridisciplinaire HAL, est destinée au dépôt et à la diffusion de documents scientifiques de niveau recherche, publiés ou non, émanant des établissements d'enseignement et de recherche français ou étrangers, des laboratoires publics ou privés. 


\title{
FEMTOSECOND INFRARED AND VISIBLE SPECTROSCOPY OF EXCESS ELECTRON IN NEAT DIMETHYLSULFIDE
}

\author{
Y. GAUDUEL, S. POMMERET, A. ANTONETTI, J. BELLONI* and J.L. MARIGNIER* \\ Laboratoire d'Optique Appliquée, Ecole Polytechnique - ENS Techniques Avancées, CNRS URA 1406 \\ - INSERM U275, F-91120 Palaiseau, France \\ ${ }^{*}$ Laboratoire de Physico-Chimie des Rayonnements associé au CNRS (URA 75), Université Orsay \\ Paris-Sud, Bâtiment 350, F-91405 Orsay cedex, France
}

\begin{abstract}
Preliminary femtosecond spectroscopic studies of primary events occurring in the neat dimethylsulfide at $294 \mathrm{~K}$ following initial energy deposition are presented. A transient induced absorbance in the infrared $(1330 \mathrm{~nm})$ appears in $120 \mathrm{fs}$ after the ultraviolet photoionization of dimethylsulfidc. Considering scavenging experiments, we assign this signal to the solvated electron $e_{\mathrm{s}}$. In the visible spectral region $(\lambda=420 \mathrm{~nm})$, a short lived species, formed in less than 300 fs has been observed. A tentative assignment of this transient component is directed toward the existence of a solvated or complexed form of the primary anion resulting from the direct electron attachment to solvent molecule.
\end{abstract}

\section{Introduction}

Femtosecond optical techniques allowing the generation of intense optical pulses from the near ultraviolet to the near infrared can bc used in the monitoring of ultrafast photophysical and photochemical reactions in polar or nonpolar liquids $[1,2]$. Indeed, when an electron of excess cnergy is created inside a molecular liquid, the interaction of the charge with surrounding molecules may lead to solvation phenomena for which polarization processes are involved. When the solvent exhibits a high electron affinity, electron attachment corresponds to the main coupling process, for which an irreversible reaction yielding a secondary anion has been defined. Numerous examples in both groups of liquids have been studied [3]. Actually, a third type of electron-liquid interaction seems to exist involving a solvation process and also a direct electron attachment to the solvent. In the liquid dimethylsulfide (DMS), solvated electrons [4] and sccondary anions $\mathrm{CH}_{3} \mathrm{SSCH}_{3}{ }^{-}$have been observed at the nanosecond regime [5]. Further studies [6] performed at picosecond time scale have permitted to conclude that the formation time of the secondary anion is shorter than $60 \mathrm{ps}$.

In neat DMS, the early formation of $\mathrm{CH}_{3} \mathrm{SSCH}_{3}{ }^{-}$and $\mathrm{e}_{\mathrm{s}}{ }^{-}$was supposed to be two embranchments of competitive reaction of a common very short lived precursor. This implies that the $\mathrm{S}^{-} \mathrm{S}^{-}$bond formation is as fast as the electron solvation itself and could occur at the femtosecond range $[1,2]$.

The aim of this work is to present preliminary report on dynamics of primary events involving single electron transfer in DMS at room temperature. More precisely, the electron solvation dynamics is investigated by 
femtosecond time-resolved absorption spectroscopy. We will discussed our data in the framework exposed above considering the likely existence of a competition between electron attachment and solvation.

\section{Experimental}

The topic of generating subpicosecond pulses has been discussed at length elsewhere [7]. In the particular experiments on DMS, one part of the amplified fundamental pulse centered around $620 \mathrm{~nm}$ is focussed into a KDP crystal to generate the second harmonic $(5 \pm 1 \mu \mathrm{J}$ at $310 \mathrm{~nm}$ ) constituting the pump beam. The ultraviolet pulse of $100 \mathrm{fs}$ duration is used to initiate the photodetachment of a subexcitation electron from DMS molecule.

The probe beam is selected in the white light corresponding to the continuum generation and tests the excited region of the sample at $10 \mathrm{~Hz}$ repetition rate. The test and the reference beams are focussed on the $400 \mathrm{~mm}$ entrance slit of a $0.25 \mathrm{~m}$ spectrometer used in the first order of a 600 grooves per mm grating and directed to two diodes. The two signals corresponding to the test and reference pulse energies at a given wavelength are sent through an electronic chain to a computer. In one sweep 100 positions of the delay line are examined and 7 of these ratios integrated for each position. Indeed, an average number of $1.5 \times 10^{5}$ shots are accumulated to allow a good signal to noise ratio on the time dependence of an induced absorption. The experiments were performed at $294 \mathrm{~K}$ in a continuously vibrating fixed volume suprasil cell ( $2 \mathrm{~mm}$ path length) so that, using a laser pulse generating rate of $10 \mathrm{~Hz}$, each laser pulse excites a new region of the sample.

The dimethylsulfide was obtained from Aldrich as $99.99 \%$ grade. Its ultimate purification over sodium and transfer by distillation under vacuum into the photoionization cell has been previously described [4]. Solutions of biphenyl $\left(0.26 \mathrm{~mol} . \mathrm{l}^{-1}\right)$ have been obtained by condensation of purified dimethylsulfide under vacuum on degassed fractions of biphenyl (Merck).

\section{Results and discussion}

\section{Femtosecond near-infrared spectroscopy}

The primary event due to the femtosecond photoionization of DMS by ultraviolet pulse is given in reaction (1). The ionization potential of DMS in the gas phase is $I P=8.685 \mathrm{eV}[8]$ :

$$
\left(\mathrm{CH}_{3}\right)_{2} \mathrm{~S} \stackrel{\mathrm{hv}}{\longrightarrow}\left(\mathrm{CH}_{3}\right)_{2} \mathrm{~S}^{+}+\mathrm{e}^{-}
$$

Then the cation and the electron of subexcitation undergo interaction with the solvent. The time dependence of the induced absorption at $\lambda=1330 \mathrm{~nm}$ is shown in Fig. 1. The appearance time of this signal is equal to $\mathrm{T}=120 \pm 10 \mathrm{fs}$ (insert of Fig. 1) and a partial decay of the absorption occurs within the first 80 ps. When an electron scavenger like biphenyl $\mathrm{Ph}_{2}\left(0.26\right.$ mol. $\left.\mathrm{I}^{-1}\right)$ is added in DMS, the decay is markedly accelerated through a monoexponential law with a time constant of $25 \pm 1$ ps. 
Figure 1 : Time dependence of the induced absorbance at $1330 \mathrm{~nm}$ after the femtosecond photoionization of neat dimethylsulfide (DMS) or dimethylsulfide + biphenyl (DMS $+\mathrm{Ph}_{2}$ 0.26 mol.1-1) by ultraviolet pulses $(310 \mathrm{~nm}$ Eexcitation $=4 \mathrm{eV}$ ). The smooth line represents the computed best fit of the experimental trace $\left(\mathrm{DMS}+\mathrm{Ph}_{2}\right)$ assuming a monoexponential signal decay with a time constant of $25 \pm 1$ ps. The initial absorbance in presence of biphenyl is lower than half of that in neat solvent and indicates an ultrafast scavenging of a precursor of the longer lived species identified as the solvated electron in DMS. The insert represents ultrafast time-resolved spectroscopy data for neat DMS. The best fit gives a solvated electron appearance time constant of $T=120 \pm 10 \mathrm{fs}$.

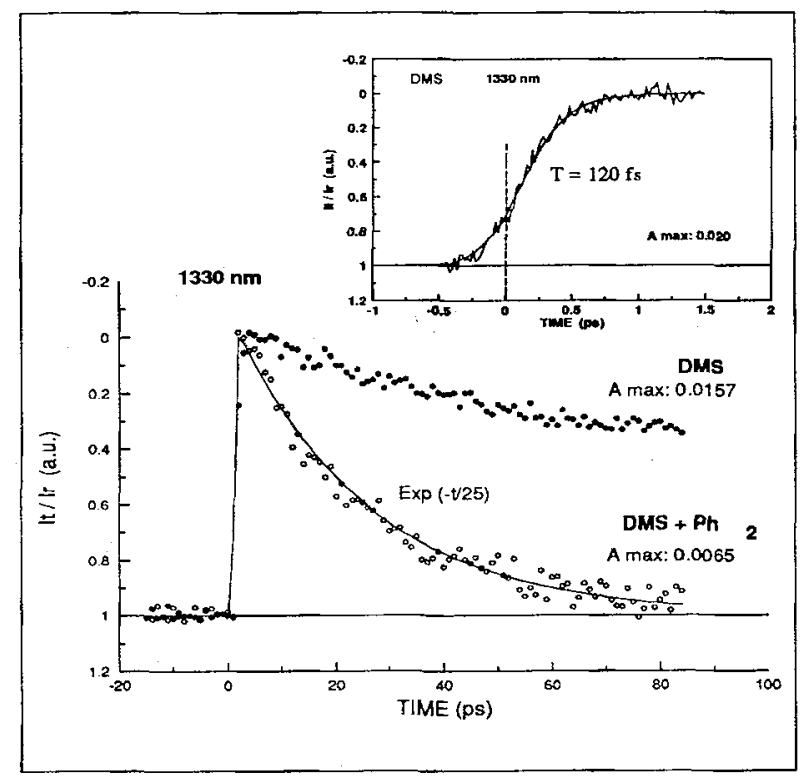

The complete recovery of the signal at long time $(t \approx 100 \mathrm{ps})$ according to a pseudo first order kinetics permits to suggest that the transient infrared component is due to a unique species. Considering previous results obtained in the nanosecond time scale [4], it is reasonable to assign the infrared signal to a solvated state of the electron. In presence of biphenyl, the fast scavenging process can be defined by the reaction (3) for which the estimate of the bimolecular rate constant is in the range value $(1.5 \pm 0.2) \times 10^{11} 1 . \mathrm{mol}^{-1} . \mathrm{s}^{-1}$.

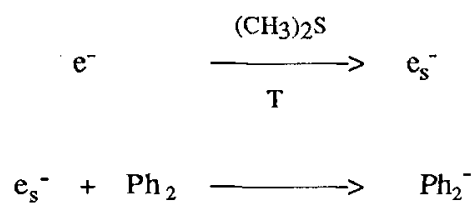

This value is in agreement with the previous value measured at nanosecond range : kes $^{-{ }^{-}+\mathrm{P}_{2}}=(1.3 \pm 0.2) \times 10^{11} 1 \mathrm{~mol}^{-1} \cdot \mathrm{s}^{-1}[4]$ and supports the assignment to $\mathrm{e}_{\mathrm{s}}^{-}$. The high bimolecular rate constant is due to the great mobility of solvated electron in such media $\left(\mu \mathrm{e}_{\mathrm{s}}^{-}=1.4 \times 10^{-2} \mathrm{~cm}^{2} \mathrm{~V}^{-1} \mathrm{~s}^{-1}\right)$. A quantitative comparison of the results obtained in absence and in presence of $\mathrm{Ph}_{2}$ also reveals that an early capture of excess electrons by biphenyl can occur before this charge gets its solvated state. Additional experiments are in progress to clearly establish this ultrafast process and would require to know the respective cross sections of multiphoton ionization of $\mathrm{DMS}$ and $\mathrm{Ph}_{2}$ at $310 \mathrm{~nm}$. Anyway the fact that the maximum absorbance is lower in presence of $\mathrm{Ph}_{2}$ would indicate that even though the cross section of $\mathrm{Ph}_{2}$ would be very high, the scavenging efficiency of $\mathrm{Ph}_{2}$ on the precursors of $e_{s}{ }^{-}$is strong enough to deplete the initial absorbance by more than $50 \%$ (Fig. 1). 


\section{Transient species in the visible.}

Femtosecond spectroscopy data on DMS solutions show that in the visible spectral range, the timedependence of induced absorption significantly differs from those obtained in the infrared. The analysis of timeresolved data in this spectral range (380 - $420 \mathrm{~nm}$ ) are conducting with a kinetical model which takes into account the convolution of the pump-probe temporal profile and the expected signal rise dynamics including the different transient species.

In the presence of $\mathrm{Ph}_{2}$ the behaviour of the signal at $412 \mathrm{~nm}$ is presented in the figure 2 . The kinetical data exhibit a short lived component and an additional slower component correlated with the decay of $e_{s}{ }^{-}$at $1330 \mathrm{~nm}$ as shown in Fig.1. We assigned the slow growth to the $\mathrm{Ph}_{2}^{-}$formation $\left(\lambda_{\max }=410 \mathrm{~nm}\right.$ and $\left.\varepsilon_{410 \mathrm{~nm}}=3.6 \times 10^{4} \quad 1 . \mathrm{mol}^{-1} . \mathrm{cm}^{-1}\right)$. A fast formation of the radical anion $\mathrm{Ph}_{2}{ }^{-}$, due to the scavenging of $\mathrm{e}_{\mathrm{s}}{ }^{-}$ precursors, may also occur at very short time and contribute to the early risetime of the signal.at $412 \mathrm{~nm}$.

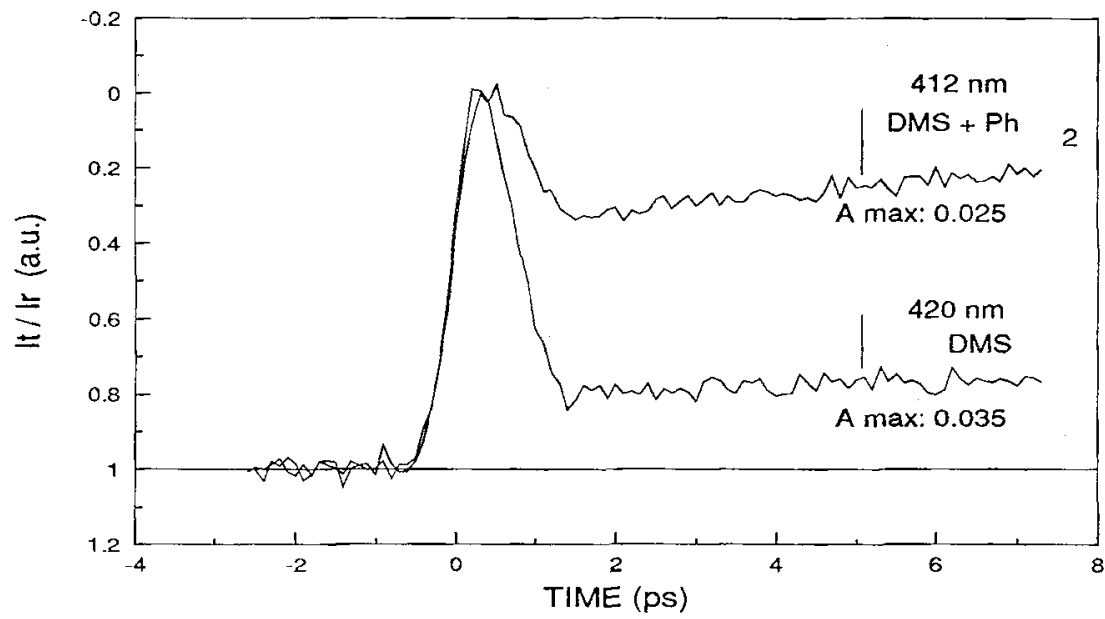

Figure 2 : Risetime of induced absorption of neat DMS or DMS $+\mathrm{Ph}_{2}(0.26$ mol.1-1) at $294 \mathrm{~K}$ following photoionization with $100 \mathrm{fs}$ laser pulses $\left(\lambda_{\text {exc }}=310 \mathrm{~nm}\right)$. The test wavelengths are 420 and $412 \mathrm{~nm}$ respectively. In presence of biphenyl, the experimental trace is a combination of at least two species : an ultrafast component, as seen at $420 \mathrm{~nm}$ in neat DMS, which is assigned to a solvated or a complexed form of the primary anion $\mathrm{CH}_{3} \mathrm{SCH}_{3}$. The incomplete recovery of the initial transmittance in presence of $\mathrm{Ph}_{2}$ is due to the rise of a long-lived component, the radical anion $\mathrm{Ph}_{2}^{-}$.

In neat DMS, the same intense ultra short-lived spectral component is observed at $420 \mathrm{~nm}$. The maximum absorbance itself is particularly intense, almost twice more than in the infrared (Fig. 3). The formation of this absorption at $420 \mathrm{~nm}$ is not as short as the pulse duration ( $<100 \mathrm{fs})$ but increases in less than $300 \mathrm{fs}$.

At this test wavelength, no species is created instantaneously i.e. within the pump-probe correlation. These dynamical results will be discussed at length in a forthcoming paper. In summary, kinetical analysis permits to exclude the contribution of directly excited or ionized states of dimethylsulfide. 


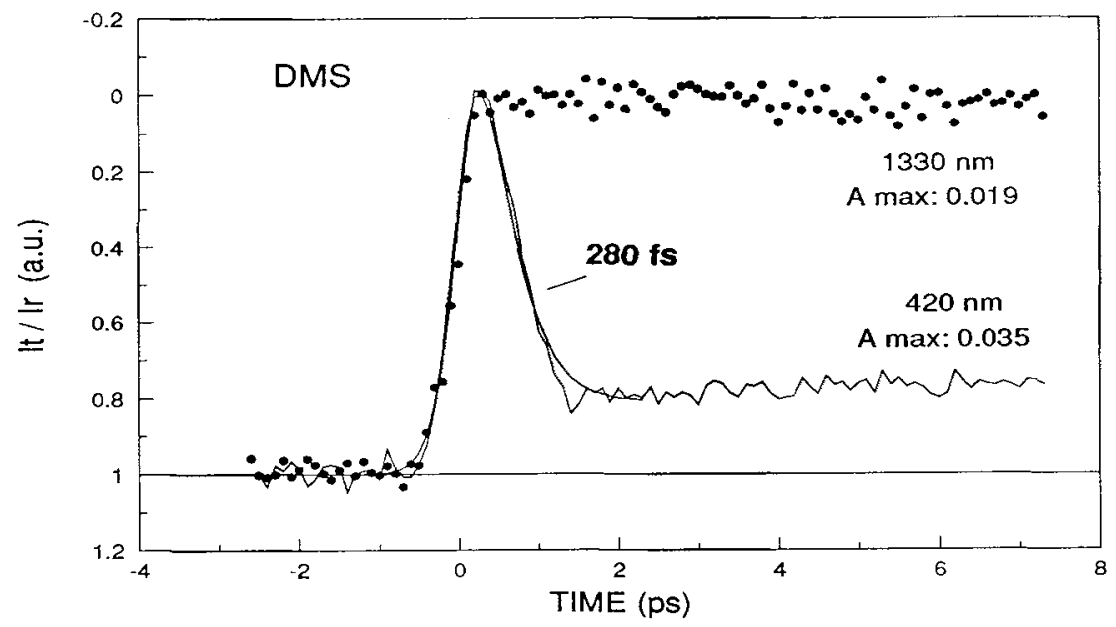

Figure 3: Typical normalized kinetics of induced absorption vs time in neat DMS at $294 \mathrm{~K}$ for two test wavelengths $(420$ and $1330 \mathrm{~nm}$ ) following femtosecond ultraviolet excitation. The maximum of absorbance at $420 \mathrm{~nm}$ is about twice that value obtained at $1330 \mathrm{~nm}$. The absorbance at long time is due at least partially to the formation of the secondary anion $\mathrm{CH}_{3} \mathrm{SSCH}_{3}{ }^{-}$. At 420 $\mathrm{nm}$, the transient species exhibits a lifetime of $280 \pm 10 \mathrm{fs}$

The experimental results rule out also the assignment of the $420 \mathrm{~nm}$ absorbance to a cation, considering that the absorption band of the primary cation $\left(\mathrm{CH}_{3}\right)_{2} \mathrm{~S}^{+}$peaks in the near $\mathrm{UV}\left(\lambda_{\max }=285 \mathrm{~nm}\right)$ and does not extend around $400 \mathrm{~nm}[8]$.

The formation of the secondary cation by complexation with a second molecule of solvent is not fast

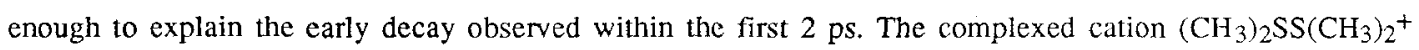
absorbing the visible light with a maximum at $480 \mathrm{~nm}[9]\left(\varepsilon_{480}\left(\mathrm{CH}_{3}\right)_{2} \mathrm{SS}\left(\mathrm{CH}_{3}\right)_{2}^{+}=(6.2 \pm 0.4) \times 10^{3} 1 . \mathrm{mol}^{-1} . \mathrm{cm}^{-1}\right)$ has been observed in picosecond pulse radiolysis experiments on neat DMS [6]. If it was produced by the ionmolecule reaction (3), the pseudo-first order time constant of this reaction would be too long ( $\tau=52 \mathrm{ps}$ ) compared to the observed relaxation dynamics at the femtosecond time scale.

$$
\left(\mathrm{CH}_{3}\right)_{2} \mathrm{~S}^{+}+\left(\mathrm{CH}_{3}\right)_{2} \mathrm{~S} \longrightarrow\left(\mathrm{CH}_{3}\right)_{2} \mathrm{SS}\left(\mathrm{CH}_{3}\right)_{2}{ }^{+} \mathrm{k}=(3.0 \pm 0.3) \times 10^{9} 1 . \mathrm{mol}^{-1} . \mathrm{s}^{-1}[9]
$$

At $420 \mathrm{~nm}$, the transient species responsible of this absorption is not directly produced by the laser excitation but may therefore be a non fully relaxed anion. As discussed in earlier works [6], the precursor may be the negative adduct $\mathrm{CH}_{3} \mathrm{SCH}_{3}{ }^{-}$, arising from an ultrafast attachment of a non-equilibrium electronic state to solvent molecules:

$$
\left(\mathrm{CH}_{3}\right)_{2} \mathrm{~S} \quad+\quad \mathrm{e}^{-} \longrightarrow \text { electron attachment }
$$

In this way the early decay of the $420 \mathrm{~nm}$ transient component can be fitted to a monoexponential law within a time constant of $\mathrm{T}=280 \pm 10 \mathrm{fs}$. This pseudo first order kinetics can be reasonably assigned to the last step of an ion-molecule reaction involving a primary negative adduct such as $\left(\mathrm{CH}_{3}\right)_{2} \mathrm{~S}^{-}$or its complexed or solvated states, respectively $\left(\mathrm{CH}_{3}\right)_{2} \mathrm{SS}\left(\mathrm{CH}_{3}\right)_{2}^{-}$or $\left(\left(\mathrm{CH}_{3}\right)_{2} \mathrm{~S}^{-}\right)_{D M S}$. 


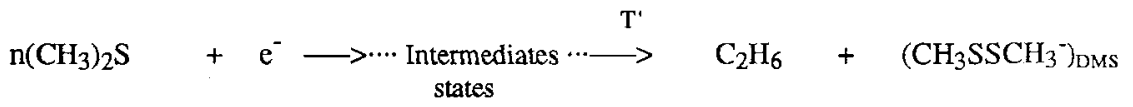

Among the other species observed at 100 picoseconds following ionization of DMS by pulse radiolysis was $\mathrm{CH}_{3} \mathrm{SSCH}_{3}{ }^{-}\left(\lambda_{\max }=420 \mathrm{~nm}[10]\right)$, almost stable after one nanosecond and which does not react with biphenyl $[5,6]$. The incomplete recovery of the signal at $420 \mathrm{~nm}$ in neat DMS (Fig. 2) could be assigned to the contribution of this anion for which a spectral band centered around $420 \mathrm{~nm}$ has been previously observed by nano and picosecond radiolysis $[5,6]$.

Additional experimental works are of interest to discriminate whether :

i) ultrafast formation of the secondary anion $\mathrm{CH}_{3} \mathrm{SSCH}_{3}{ }^{-}$may involve pre-structurated dimers in the solvent .

ii) early reaction of the primary anion with electron scavenger $\left(\mathrm{Ph}_{2} \ldots\right)$ can occur concomitantly to the secondary anion formation.

In conclusion, we address the problem of resolving at the femtosecond time scale the absorption by the excess electron in neat DMS starting from injection up to full solvation or attachment.

The first results obtained in photoionized dimethylsulfide at the femtosecond range demonstrate the existence of an ultrafast dynamics of electron solvation (solvation time $=120$ fs at $294 \mathrm{~K}$ ). This fully relaxed electron absorbs in the near infrared and is readily scavenged by the biphenyl. In the visible $(420 \mathrm{~nm})$, a very short lived species (lifetime $280 \mathrm{fs}$ ) is tentatively assigned to a precursor of the secondary anion $\mathrm{CH}_{3} \mathrm{SSCH}_{3}{ }^{-}$. This precursor (solvated or complexed form of $\left(\mathrm{CH}_{3}\right)_{2} \mathrm{~S}^{-}$), will be generated through an electron reaction with the solvent. Its optical absorption spectrum seems to extend in the same range of wavelength as that of $\mathrm{CH}_{3} \mathrm{SSCH}_{3}{ }^{-}$ and possibly of $\left(\mathrm{CH}_{3}\right)_{2} \mathrm{SS}\left(\mathrm{CH}_{3}\right)_{2}{ }^{+}$and has to be established. Experimental works are in progress to investigate primary events leading to dual behaviour of excess electron in dimethylsulfide.

Acknowledgments : This work has been partially supported by grant from Direction des Recherches (DRET, Paris).

\section{References}

* Correspondence should be sent to Y. Gauduel

1/ GAUDUEL Y., MIGUS A., MARTIN J.L. , LECARPENTIER Y. and ANTONETTI A., Ber. Bunsenesg. Phys. Chem. 89 (1985) 218

12/ For a recent and detailed review see the special issue of J. Opt. Soc. Am., B, $7 \mathrm{n}^{\circ} 8$ (1990), and references therein.

B/ BELLONI J. AND MARIGNIER J.L., Rad. Phys. Chem. 34 (1989) 157 and references therein

14/ MARIGNIER J.L, BELlONI J. AND DELAIRE J., Chem. Phys. Lett. 59 (1978) 237

15/ MARIGNIER J.L. AND BELLONI J., J. Phys. Chem. 85 (1981) 3100

/6/ BeLlONI J., MARIGNIER J.L., KATSUMURA Y. and TABATA Y., J. Phys. Chem. 90 (1986) 4014

II GAUDUEL Y., MIGUS A. and ANTONETTI A. In "Chemical reactivity in liquids ; fundamental aspects" Eds. M. Moreau and P. Turcq (Plenum Press, New-York, 1985) p 15-22.

18/ ROSENSTOCK H.M., DRAXL K., STEINER B.W. and HERRON J.T,, J. Phys. Chem. Ref. Data, Suppl. 1 (1977) 6.

9/ CHAUdHRI A.A., GÖBL M. , FREYHOldT T. and ASMUS K.D., J. Am. Chem. Soc. 106 (1984) 5988.

/10/ KARMANN W. , GRANZOW A , MEISSNER G. and HENGLEIN A., Radiat. Phys. Chem. 1 (1969) 395. 